\title{
Toz metalurjisi ile Üretilen NiTi Alaşımına Al’un Etkisi
}

\author{
Musa KILIÇ* \\ Batman Üniversitesi, Teknoloji Fakültesi, Makine-Imalat Mühendisliği Bölümü, Batman \\ (ORCID: 0000-0001-5808-6917)
}

\begin{abstract}
$\ddot{\mathbf{O z}}$
Bu çalışmada, Ti-50,5Ni-xAl(x=0, 2, 4) alaşımı toz metalürjisi yöntemlerinden SHS ile üretildi. Üretilen NiTiAl alaşımlarında $\mathrm{Al}$ oranının numunelerin mikroyapılarına ve mikrosertliklerine etkileri detaylı bir şekilde incelendi. Mikroyapı analizleri optik mikroskobu(OM) ve taramalı elektron mikroskobu (SEM) ile faz bileşenleri ise Enerji Dağılımlı Spektroskopi (EDX) ve X-Işınları Kırınım Cihazı (XRD) analizi ile tespit edildi. Sertlik ölçüm testleri Vickers (Hv) mikrosertlik ölçüm cihazında yapılmıştır. Ateşleme sonrası ekzotermik reaksiyon sonucunda başlayan yanma reaksiyonu esnasında yüzeyde oluşan sıcaklık değişimi lazer sıcaklık ölçüm cihaz ile tespit edildi. Optik mikroskop(OM) analizleri sonucunda Al içeriğinin artmasına bağlı olarak gözenek oranın arttığı gözlenmektedir. Ayrıca Al ilavesiz NiTi numunesinde ise yanma kanallarının yoğun olduğu görüldü. Hem EDX hem de XRD anliz sonuçlarında alaşımlarda $\mathrm{NiTi}, \mathrm{NiTi}_{2}$ ve $\mathrm{Ti}_{3} \mathrm{Al}$ fazlarının varlığı tespit edildi. Yüzey sıcaklık ölçüm sonuçlarında yanma reaksiyonu en düşük $550^{\circ} \mathrm{C}$ elde edilirken en yüksek ise $1250^{\circ} \mathrm{C}$ ölçüldü. Mikrosertlik ölçüm sonuçlarında en düşük sertlik değeri $176.8 \mathrm{HV}_{0,5}$ ağ. \%4 Al numunesinden elde edilirken, en yüksek değer ise $301.7 \mathrm{HV}_{0,5} \mathrm{NiTi}$ numunesinde ölçüldü.
\end{abstract}

Anahtar kelimeler: Ni-Ti-Al, NiTi-Al, mikroyapı, gözeneklilik, yanma reaksiyonu.

\section{The Effect of Al of NiTi Alloy Fabricated by Powder Metallurgy}

\begin{abstract}
In this study, Ti-50,5Ni-xAl $(\mathrm{x}=0,2,4)$ alloy is produced by SHS which is one of the powder metallurgy methods. The effects of $\mathrm{Al}$ ratios on the microstructure and microhardness of the samples in the produced NiTiAl alloys are examined in detail. The analysis of microstructure is determined by optical microscope and scanning electron microscope (SEM) and phase components are analysed by Energy Dispersive spectroscopy (EDX) and X-Ray Diffraction Device (XRD). The measurement tests of hardness are carried out by using Vickers (Hv) microhardness test device. The temperature change on the surface during the combustion reaction which started as a result of the exothermic reaction after ignition is measured by a laser temperature measuring device. Based on the results of optical microscope $(\mathrm{OM})$ analysis, the pore ratio has increase with the increase ratio of $\mathrm{Al}$ content. Moreover, it is observed that the combustion channels are intense fort he NiTi sample without $\mathrm{Al}$ content. At both of the results of EDX and XRD analysis, it has been noticed the presence of $\mathrm{NiTi}, \mathrm{NiTi}_{2}$ ve $\mathrm{Ti}_{3} \mathrm{Al}$ phases in the alloys. In surface temperature measurement results, the lowest $550{ }^{\circ} \mathrm{C}$ combustion reaction was obtained, while the highest $1250{ }^{\circ} \mathrm{C}$ was measured. For the microhardness measurement results, the lowest value is observed as 176.8 $\mathrm{HV}_{0,5}$ from the $\% 4 \mathrm{Al}$ alloy samples while the highest value is measured $301.7 \mathrm{HV}_{0,5}$ from NiTi sample.
\end{abstract}

Keywords: Ni-Ti-Al, NiTi-Al, microstructure, porosity, combustion reaction.

\section{Giriş}

Eş atomik konsantrasyona sahip NiTi şekil hafizalı alaşım, uygulanan deformasyon sonrası orijinal şekline geri dönme yeteneği ile benzersiz özelliklere sahip en önemli şekil hafizalı alaşımlardan(SMA) biridir [1-3]. NiTi alaşımlar şekil hafıza özellikleriyle birlikte yüksek korozyon direnci [4], biyouyumluluk, mükemmel aşınma direnci [5], süper elastiklik gibi eşsiz özelliklere sahiptir. $\mathrm{Bu}$

*Sorumlu yazar: musa.kilic@ batman.edu.tr
Geliş Tarihi: 15.12.2020, Kabul Tarihi: 18.02.2021 
özellikleri sayesinde makine imalat [6], otomotiv, robotik ve biyomedikal uygulamalar [7], gibi geniş bir kullanım alanına sahiptir.

Malzeme biliminde alaşımlar birçok yöntem ile üretilmektir. Bu yöntemler arasında; ergitme, reaktif sinterleme, geleneksel sinterleme [1], sicak izostatik presleme [8], kıvılcım plazma sinterleme [9] ve SHS(kendi kendine ilerleyen yüksek sıcaklık sentezi) [10] yöntemleri farklı araştırmacılar tarafindan kullanılmaktadır. Bu yöntemler arasında yer alan SHS yöntemi pahalı ekipmana ihtiyaç duyulmadan ekzotermik reaksiyon sayesinde numunelerin üretimi basit bir şekilde gerçekleşmektedir. Gunter vd. [11] SHS yöntemini kullanarak gözenekli NiTi alaşımını üretmişlerdir. İşlem sonrası SHS reaksiyonunun yüzeysel metalik fazların belirlenmesinde kolaylık sağladığı, gözenekli alaşımın spesifik yüzey katmanı ile yüksek biyouyumluluk sağladığını ifade etmiştir. Nikel-titanyum değişim dönüşüm sıcaklıkları içeriğindeki oranlara göre değişim sergiler, Ni içeriğinde $\% 0.1$ oranında bir değişim dönüşüm sıcaklığını $10{ }^{\circ} \mathrm{C}$ etkileyebilir. Seçilen alaşım elementleri (demir, kobalt, vanadyum, krom, manganez, alüminyum ve tantal) dönüşüm sıcaklıklarını düşürdüğü bilinmektedir [12]. Dagdelen vd. [13] ergitme tekniğiyle NiTiNb alaşımını üretmişlerdir. Çalışma sonucunda $\mathrm{Nb}$ artışını ve Ni oranının azalması faz dönüşümünü arttırdığını, Ms sıcaklığını ise oda sıcaklığının altına düşürdüğü bu nedenle bu malzemenin süper elastik implant olarak kullanılabileceğini ifade etmişlerdir. Ni-Al-Ti üçlü sistemi nikel esaslı alaşımın önemli bir alt sistemidir. Bu malzemeler yüksek sıcaklık dayanımı, sürünme dayanımı, oksidasyon ve korozyon direnci gibi üstün özellikleri sayesinde havacılık ve yüzey kaplama endüstrisinde yaygın bir kullanım alanına sahiptir $[14,15]$. Farklı Al ilavesine sahip alaşımlar ve Al ilavesindeki artışın, tane inceltmesini desteklediğini ve makro-sertlik değerlerini arttırdığını bulmuşlardır. Ayrıca Al ilavesi, Ni-zengin NiTi alaşımlarının stabilitesini en az $500^{\circ} \mathrm{C}$ 'ye kadar arttırdığ 1 bildirilmiştir [16]. Zhao vd. [17] elektro çöktürme yöntemi ile Ni-xAl-yTi kaplama tabakas1 üretmişlerdir. Ni-xAl-yTi kaplamaların korozyon direnci ve mikrosertliği artan partikül konsantrasyonu ile arttığını bildirmişlerdir. Kim vd. [18] Al-Ni-Ti amorf alaşımlarının oluşum ve kristalleşme davranışlarını araştırmışlardır. Geliştirilmiş süneklik, yalnızca amorf matrikse birkaç nanometre boyutunda $\mathrm{Al}$ kristalinin gömülmesiyle elde edilebilir. Al-Ni-Ti amorf alaşımlarının sünekliğinin alaşıma güçlü bir şekilde bağlı olduğunu göstererek iyi bir süneklik, yani kırılma olmadan $180^{\circ}$ bükme sergilediğini ifade etmişlerdir. Ayrıca, bükülme esnekliği olmayan Al-Ni-Ti amorf alaşımı difüzyon kontrollü çekirdeklenme ve fcc-Al ve metastaz fazların büyümesi ile kristalleştiğini belirtmişlerdir. Yapılan literatür araştırması sonucunda NiTi-Al intermetalik bileşiklerinden üretimi üzerine farklı yöntemler ile faz dönüşümleri, kaplama veya sayısal modelleme çalışmaların daha yoğun olduğu belirlenmiştir [19-21].

Bu çalışmada kendi kendine ilerleyen yüksek sıcaklık sentezlemesi (KKIYSS) tekniği ile NiTiAl intermetalik bileşiği üretilmiştir. Sentez sonrası numuneler optik mikroskop, SEM-EDX ve XRD analizleri yapıldı. Mikrosertlik ölçüm değerleri ve yüzeyde meydana gelen sıcaklık ölçüm sonuçlarıyla mikroyapı sonuçları karakterize edildi.

\section{Materyal ve Metot}

$\mathrm{Bu}$ çalışmada Tablo 1'de verilen toz elementlerinden istenilen oranlarda kullanılarak Ti-50,5Ni$\mathrm{xAl}(\mathrm{x}=0,2,4 \%$ ağ.), alaşımları KKIYYSS yöntemi ile üretildi.

Tablo 1. Ni, Al, Ti tozlarına ait genel özellikler

\begin{tabular}{cccccc}
\hline Malzeme & $\begin{array}{c}\text { Ağırlıça } \\
\text { Saflık } \\
\text { Derecesi }(\%)\end{array}$ & $\begin{array}{c}\text { Toz } \\
\text { Boyutu } \\
(\text { Mesh })\end{array}$ & $\begin{array}{c}\text { Erime } \\
\text { Sicaklığı } \\
\left({ }^{\circ} \mathrm{C}\right)\end{array}$ & $\begin{array}{c}\text { Özgül } \\
\text { Ağırlık } \\
\left(\mathrm{gr} / \mathrm{cm}^{3}\right)\end{array}$ & $\begin{array}{c}\text { Atom } \\
\text { Kütlesi } \\
(\mathrm{gr} / \mathrm{mol})\end{array}$ \\
\hline $\mathrm{Ni}$ & $\mathbf{9 9 . 5}$ & $\mathbf{- 3 2 5}$ & $\mathbf{1 4 5 3}$ & $\mathbf{8 . 9 0 8}$ & $\mathbf{5 8 . 7 1}$ \\
$\mathrm{Al}$ & $\mathbf{9 9 . 5}$ & $\mathbf{- 3 2 5}$ & $\mathbf{6 6 0 . 4}$ & $\mathbf{2 . 7}$ & $\mathbf{2 6 . 9 8}$ \\
$\mathrm{Ti}$ & $\mathbf{9 9 . 5}$ & $\mathbf{- 3 2 5}$ & $\mathbf{1 6 8 0}$ & $\mathbf{4 . 5 0 7}$ & $\mathbf{4 7 . 9}$ \\
\hline
\end{tabular}

Üretim öncesi hassas terazide Ni'ce azalan Al'ca artan bir oranda tartılan tozlar 12 saat süresince karıştırıldı. Tozlar $150 \mathrm{Mpa}$ basınç altında soğuk olarak preslendi. Hazırlanan briketler 12 lt/dk akış hızında Ar gazı atmosferine sahip ateşleme odasına dik bir şekilde yerleştirildi (Şekil 1). SHS işlemi sonrası üretilen numuneler metalografik incelemeler için hassas kesme makinesinde kesildi. Daha sonra farklı boyutlarda $\mathrm{SiC}$ zımparalar ile zımparalama ve son olarak $1 \mu \mathrm{m}$ 'luk elmas pasta kullanılarak 
çuha' da parlatıldı. Parlatma işlemi sonrası $\% 30 \mathrm{HNO}_{3}+\% 20 \mathrm{HF}+\% 50 \mathrm{Saf}$ su çözeltisinde 5 sn süreyle dağlandı. Dağlama işlemi sonrası numune mikroyapıları, Nicon marka optik mikroskop (OM) cihazı ve LEO marka EVO 40 VP model taramalı elektron mikroskobu (SEM) yardımıyla incelendi.

Numunelerin elementel dağılımları BRUKER125 eV marka EDX cihazı ile faz bileşenleri ise analizi (XRD, Rigako Rad-B D-Max 2000) 10 ila 90 derece tarama aralığı ve 2 theta açısına sahip XRay difrakometre kullanılarak belirlendi. Mikrosertlik ölçüm sonuçları EMCO-TEST marka mikrosertlik cihazında gözenek kenarlarından 7 farklı noktadan Vickers $\left(\mathrm{HV}_{0,5}\right)$ cinsinden ölçüldü. Ark oluşumuyla birlikte yüzeyde oluşan yanma reaksiyonuna ait sicaklık değerleri $550-1800^{\circ} \mathrm{C}$ arasında sıcaklık ölçümü yapabilen IMPAC Marka lazer test cihazı ile belirlendi.

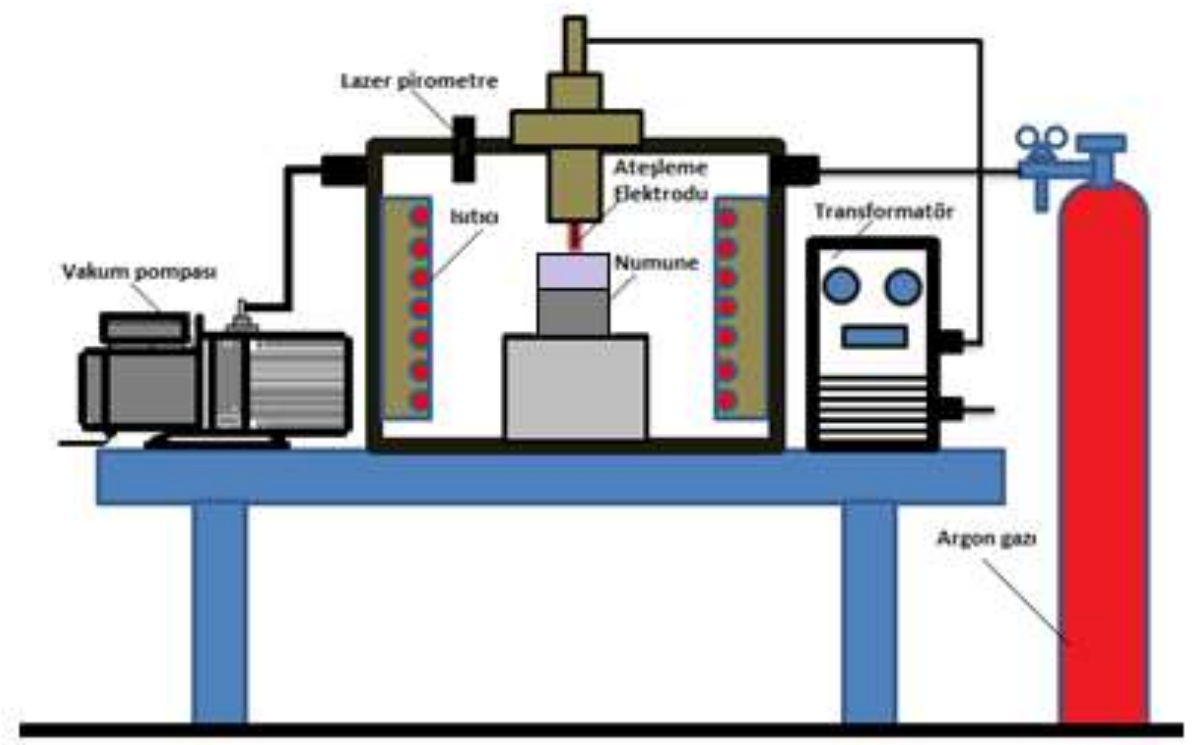

Şekil 1. Ateşleme odası [22].

\section{Bulgular ve Tartışma}

Yüzeyde oluşan sıcaklık değişimine Şekil 2'de yer verilmiştir. Ateşleme sonrası başlayan yanma ekzotermik reaksiyon etkisi ile numune boyunca ilerledi. Yanma reaksiyonu esnasında ulaşılan başlangıç sıcaklık değerleri sırasıyla minimum 582, 627 ve $612^{\circ} \mathrm{C}$ olurken maximum sicaklık değerlerinin ise sırasıly 1245,1197 ve $1238^{\circ} \mathrm{C}$ olduğu tespit edildi.

Ark yardımıyla başlatılan ateşleme ve akabinde oluşan kıvılcım şeklinde başlayan yanma reaksiyonu $550-650{ }^{\circ} \mathrm{C}$ sicaklık aralığında olduğu tespit edildi (Şekil 3). Geleneksel reaksiyon sentezlemesinde genellikle reaksiyon sıcaklığı için (genellikle ötektik sıcaklığı $640^{\circ} \mathrm{C}$ 'nin üzerinde)bir firın içinde yeşil kompaktların ısıtılmasıyla birlikte, reaksiyon başlar. Oluşan yanma reaksiyonu ergime noktasının üstündeki bir 'adyabatik' sıcaklığa kadar sıcaklığı yükseltir [23].

Reaksiyon max. sıcaklığa ulaştıktan sonra dalga halinde ilerleyen yanma ekzotermik reaksiyon sonucunda tüm numune boyunca kendi kendine ilerler. Sıv1 hale geçen bir bölge diğer bölgenin sıcaklığını yükselterek sıvı hale geçirir. Böylece dalganın ön yayılım yanma hızı artar. Nikelin alüminyum sıvısında erimesinden sonra, alüminyumdaki nikel sıvı çözeltisi, ilave 1sı salarak yanma dalgası cephesinin sıcaklığını arttırır ve oluşan kimyasal reaksiyon mekanizması titanyum ile reaksiyona girmeye başlar [24]. İlerleme, numune boyunca tamamlandıktan sonra sıcaklık düşüşe başlayarak katılaşma sürecini başlatmış olur. Bu sıcaklık değerlerinin gözenekli bir Ni-Ti-Al üretimi için yeterli olduğu Şekil 4'te verilmiş olan makro resimlerden de görülmektedir. 


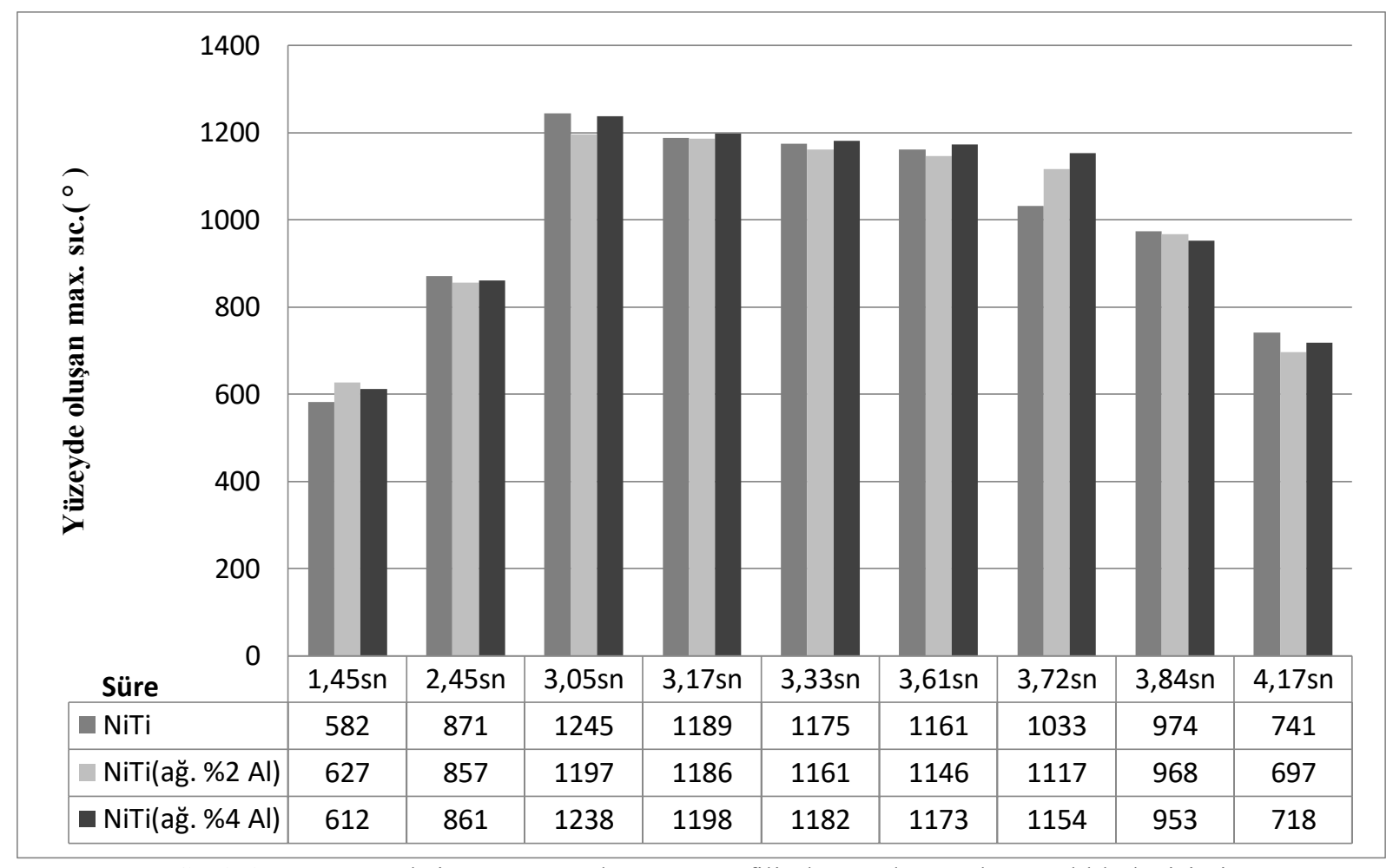

Şekil 2. Yanma reaksiyonu sırasında yüzey profilinde meydana gelen sıcaklık değişimi

Şekil 3'te ağ. \%2 Al ilaveli numuneye ait yanma reaksiyonunun görüntülerine yer verilmiştir. Reaksiyon başlamasıyla birlikte tüm numune boyunca ekzotermik reaksiyon ile dalga halinde ilerleyerek toz kompaktının ürüne dönüşmesini sağladığı gözlenmiştir.

İlk ateşleme ile birlikte kıvılcımların oluştuğu alev ön hızında bir artışın meydana geldiği gözlenmiştir (Şekil 3). Bunun başlica nedeni katman katman 1s1 transferini geliştiren ve yanma dalgasının hızlanmasını sağlayan reaktant parçacıkları arasındaki yakın temasın artmasından dolayıdır [25].

Şekil 3’te görüldüğ̈̈ üzere 1,45 sn civarında üstten ateşleme işlemi sonrasında yanma reaksiyonu alt yan kısımda kıvılcım şeklinde küçük bir alev ile başlamışıır. Ancak asıl yanma ve reaksiyonun büyümesi 3,05sn civarında gerçekleştiği görüldü. Bu olay esnasında oluşan sıcaklık $900^{\circ} \mathrm{C}$ civarında ölçülmüştür. Yanma reaksiyonu $1,45 \mathrm{sn}$ ve 3,33sn içerisinde numune boyunca ilerlemiştir. Yanma dalgasının sonlanması ile birlikte 3,61sn-5,91sn aralıklarında hızla soğumaya başlamıştır. Reaksiyonun tamamlanmasıyla birlikte NiTiAl alaşımından oluşan ürün elde edilmiştir.

Ateşleme sonrası üretilen ürünlerin makro görüntüleri Şekil 4(a, b, c)'te verilmiştir. Saf NiTi numunesinin yoğun kanallardan oluştuğu kanalların özellikle orta kısımda daha yoğunlaştığı görülmektedir. Termal dalgaların artmasıyla birlikte meydana gelen ergimeden dolayı numune yüzeyinde yanma kanalları oluşur. Bu da yapının tamamında daha yüksek yoğunluk ve daha az gözenek oluşumunu sağlar [26]. Yanma kanallarının yönü yanma ilerlemesine dik bir şekildedir. Kaya vd. [27] yanma kanalları numune ekseni boyunca veya paralel oluştuğu zaman numunelerin basma dayanımının maksimum olmasını sağladığını belirtmişlerdir. \%2 Al içeriğine sahip Ni-Ti-Al'da ise yanma kanallarıyla birlikte düşük oranda gözeneklerin varlığı gözlendi.

\% $4 \mathrm{Al}$ içeriğine sahip NiTiAl numune resminden de görülüğü üzere yapıda kanal oluşumuna kıyasla gözeneklerin yoğun olduğu görülmektedir. Gözeneklerin yoğunluğunun $\mathrm{Al}$ oranındaki artı̧̧a bağlı olarak artış sergilediği gözlemlenmiştir (Şekil 4). Dong vd. [28] İntermetalik alüminitlerde gözenek oluşumu üzerinde ilave edilen $\mathrm{Al}$ içeriğinin etkili olduğunu belirtmişlerdir.

Mikroyapı resimlerinden anlaşıldığı üzere Al içeriğinin artmasına bağglı olarak gözenek oranında bir artış meydana gelmiştir (Şekil 5). Bununla birlikte gözenek oluşumunun diğer nedenleri arasında: kullanılan tozların saflı̆̆ı, tozların karışım oranı, toz kompaktlama sırasındaki başlangıç gözenekliliği, ürünün nispi yoğunluğu, kompaklanmış reaktant içerisinde hapsolmuş gazlar, gözeneklerin termal göçü, sıkıştırma basıncı ve hızı, faz dönüşümleri esnasında hacimsel değişiklikler ve büzülmelere bağlı oluşan 
gözenekler ve elementlerin katı hal difüzyonuna (kirkendall etkisi olarak bilinir) bağlı olarak oluşan gözeneklerdir $[9,12]$.

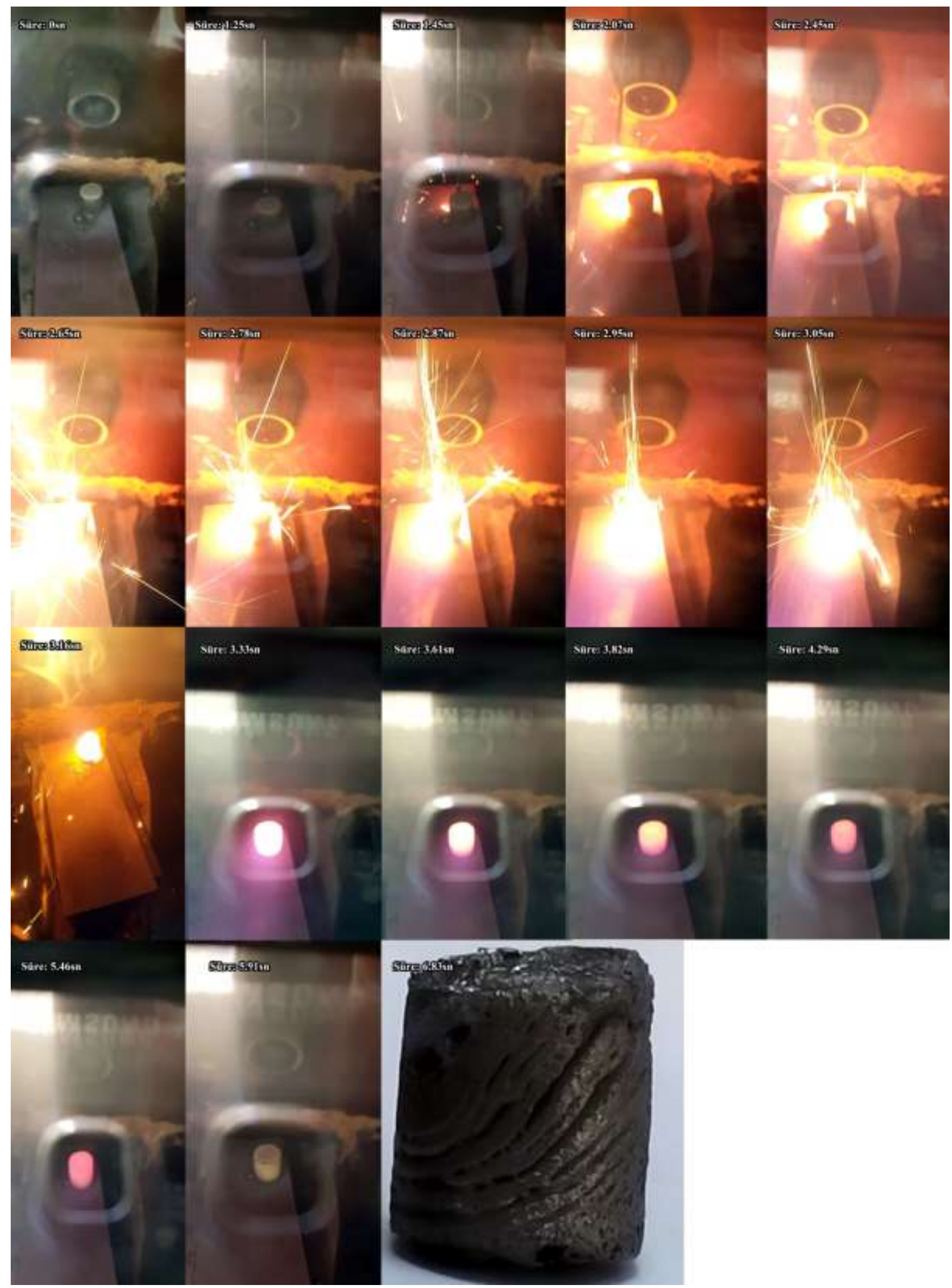

Şekil 3. ağ. \%2 Al ilaveli numuneye ait yanma reaksiyonunun görüntüleri ve üretilen numuneye ait makro resim 


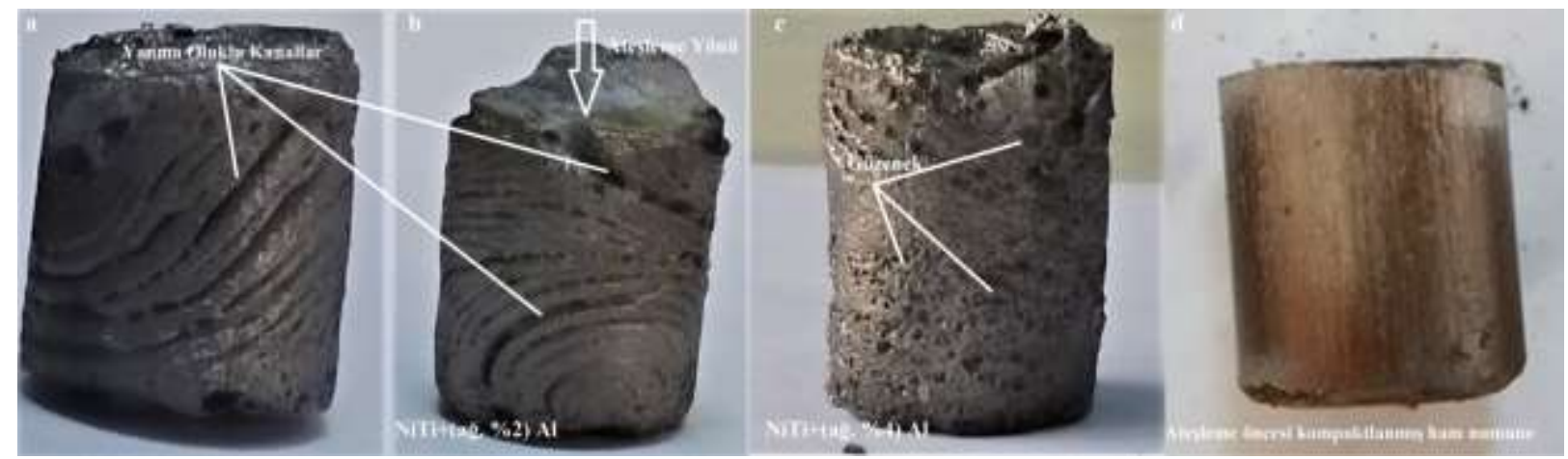

Şekil 4: Ateşleme sonrası üretilmiş numunelere ait resimler
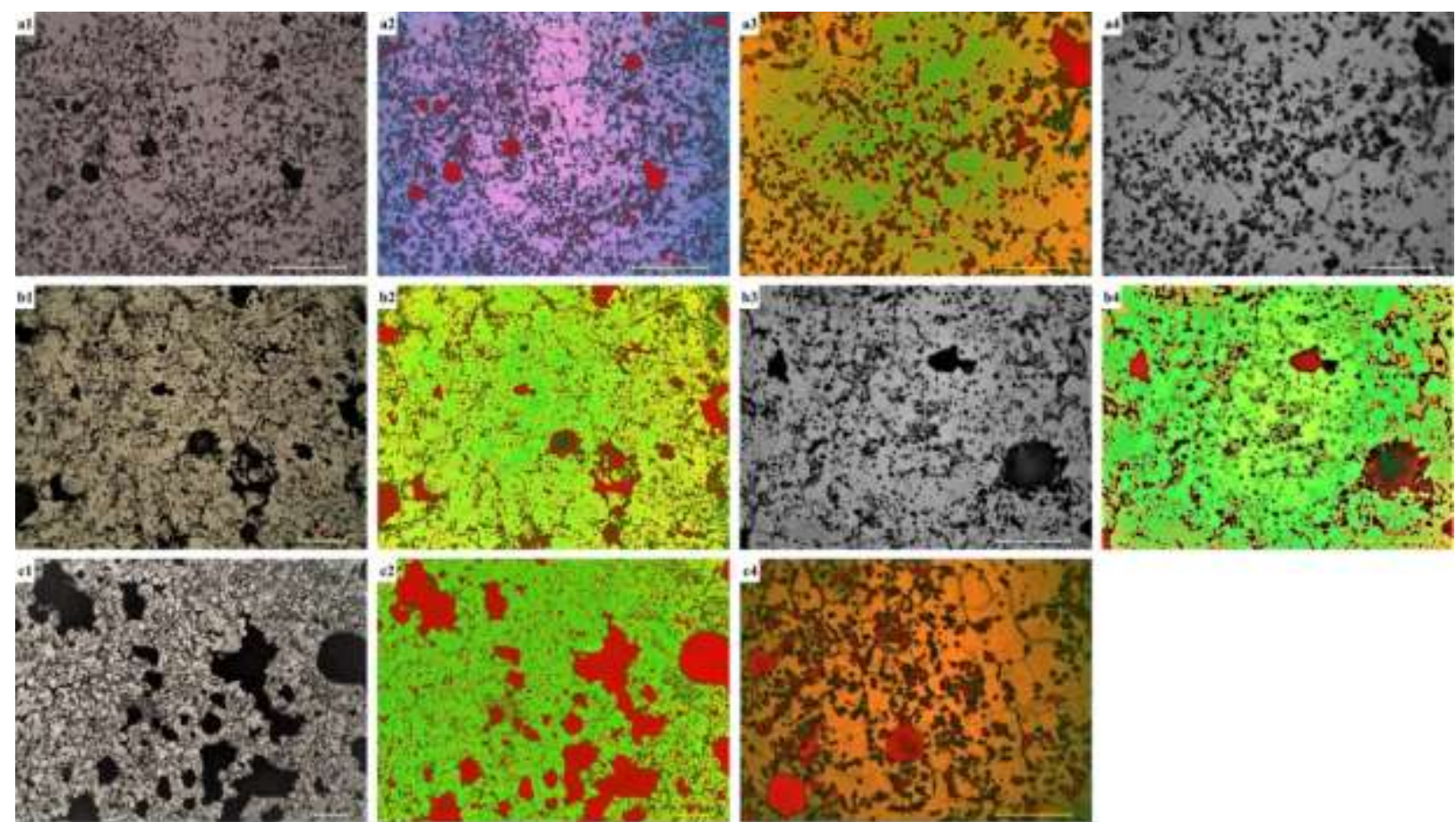

Şekil 5. a) NiTi, b) NiTi-ağ.\%2(Al) ve c) NiTi-ăg.\%4(Al)

Al ilavesiz saf NiTi numunesine ait mikroyapıda (Şekil 5 a1-a4) gözenek oranının düşük olduğu, oluşan gözeneklerin ağ.\%2 Al ve ağ.\%4 Al içeriğine sahip numunelere kıyasla küçük boyutlarda olduğu görülmektedir. Ağıllıkça \%4 Al içeriğine sahip NiTiAl numunesinde gözenek oranının diğer iki numuneye göre daha fazla olduğu, ayrıca gözenek boyutunun da aynı şekilde daha geniş olduğu görülmektedir (Şekil 5 c1-c4).
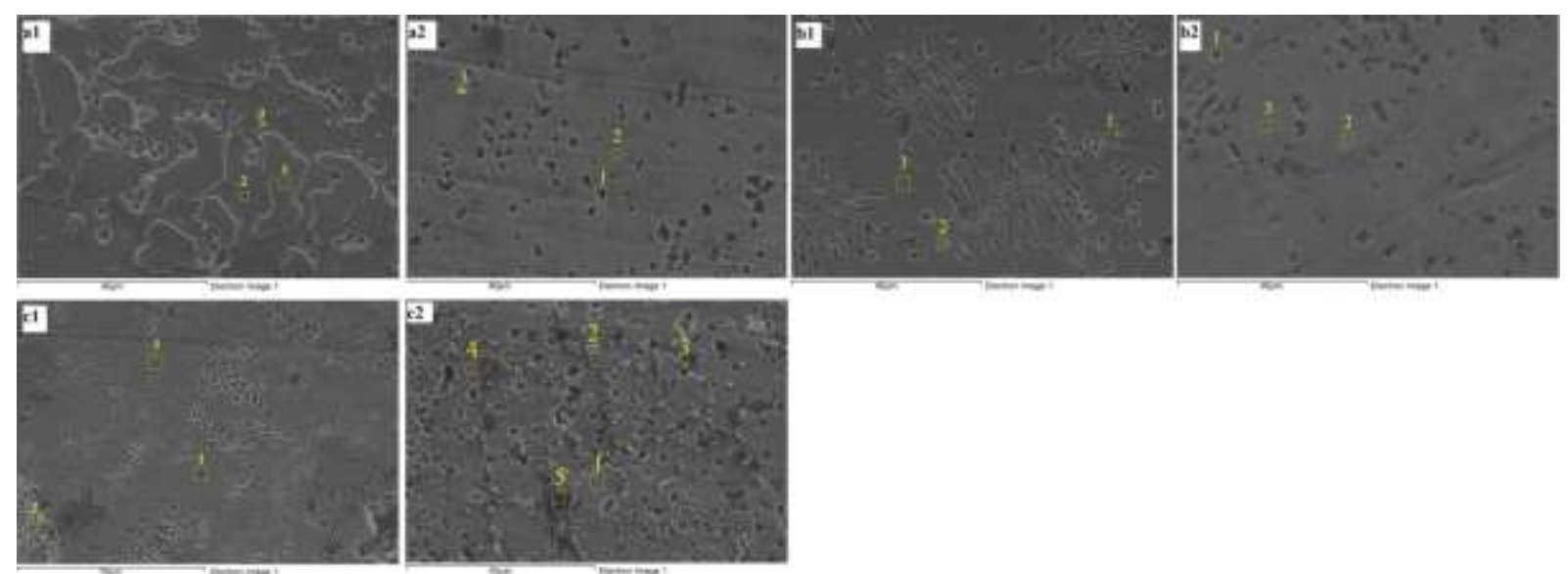

Şekil 6. a) NiTi, b) NiTi-wt.\%2(Al) ve c) NiTi-wt.\%4(Al) numunelerine ait SEM görüntü analizleri 
Numunelere ait SEM analiz sonuçlarına Şekil 6 (a1,a2,b1,b2,c1,c2) yer verilmiştir. Ayrıca Şekil 7'de ise EDX analiz sonuçlarına ait grafiğe yer verilmiştir. Numunelerin mikroyapı gelişimi Al içeriğine bağlı olarak farklı yapı sergilediği gözlenmiştir. EDX analiz sonuçları Şekil 8'da verilmiş olan üçlü faz diyagramı yardımıyla değerlendirilerek mevcut fazlar tespit edilmeye çalışılmıştır. Şekil 6(a1)'de yaprak şekilli adacıkların \%31.48 Ti, \%68.52 Ni elementlerinden oluştuğu bu değerlerin $\mathrm{Ni}_{3} \mathrm{Ti}+\mathrm{Ni}$ fazına karşılık geldiği üçlü faz diyagramı ile tespit edilmiştir.

Yaprak şekilli adacıklar arasında alınan EDX sonuçları 2. noktanın NiTi fazından oluştuğu tespit edilmiştir. Aynı şekilde 3. nokta yapı içerisinde görülen küçük noktalardan alınmış olup \%49.49 Ti, $\% 50.51 \mathrm{Ni}$ elementlerinden oluştuğu bu sonucun NiTi fazına ait olabileceği anlaşılmaktadır. Şekil 7a2'de ise büyük ve küçük parçacıklı yapıların oluştuğu görülmektedir.

EDX analiz sonuçlarından bu parçacıkların Ti'ca zengin $\mathrm{NiTi}_{2}+\mathrm{NiTi}$ fazından oluştuğu, gri bölgenin ise (2. nokta) Ni'ce zengin NiTi alaşımı olduğuna işaret etmektedir(Şekil 8). Şekil 6 (b1-b2)'de yer verilmiş olan ağ.\%2 Al numunesinde mikroyapıda farklı dendrit yapıların oluştuğu gözlenmiştir. Dendrit yapısı ve çevresinden alınan EDX sonuçlarına bakıldığında (Şekil 6b1) 1. noktanın Ti'ca zengin olduğu(Ti \%59.47, Ni \%21.78, Al \%18.75) bu bölgenin $\mathrm{Ti}_{3} \mathrm{Al}+\mathrm{NiTi}_{2}$ fazından oluşabileceği belirlendi. Dendtritik yapı üzerinden alınmış olan 2. noktadaki sonuçlara göre dendrit yapının (Şekil 8) $\mathrm{Ti}_{3} \mathrm{Al}$ fazın eşit olabileceği düşünülmektedir. $1080^{\circ} \mathrm{C}$ sıcaklıklarda mikroyapı $\mathrm{NiTi}$ matris fazı ve $\mathrm{Ti}_{2} \mathrm{Ni}, \mathrm{Ni}_{3} \mathrm{Ti}$ güçlendirme fazından oluşur.

Sıcaklık $1200^{\circ} \mathrm{C}$ ulaştığında titanyum ve alüminyum açısından zengin üçlü matris fazları $\mathrm{Ti}_{3} \mathrm{Al}(\mathrm{Ni}), \mathrm{NiAl}(\mathrm{Ti}), \mathrm{NiTi}(\mathrm{Al})$ ve $\mathrm{AlNi}_{2} \mathrm{Ti}$ oluşmaya başlar $[29,30]$. Şekil 6 (c1,c2)'da ağ.\%4 Al ilavesine sahip numuneye ait SEM görüntüsü yer almaktadır. Gözenek yoğun bir yapıdan oluşmuştur. Gözenekler c2'de daha yoğundur. EDX sonuçları dikkate alındığında 1. nokta NiTi 2 (\%45.4 Ti, 38.39 $\mathrm{Ni}, 16.21 \mathrm{Al}), 2$. nokta Ni $3 \mathrm{Ti}+\mathrm{NiTi}(\% 38,64 \mathrm{Ti}, 51.12 \mathrm{Ni}, 10.24 \mathrm{Al}), 3$. noktanın ise $\mathrm{NiTi}_{2}+\mathrm{NiTi}(\% 48,59$ $\mathrm{Ti}, 42.11 \mathrm{Ni}, 9.3 \mathrm{Al}$ ) fazlarına eşit olabileceği belirlenmiştir.

Şekil 6 (c2)'daki SEM ve EDX analizlerinde ise yapının $\mathrm{Ni}_{3} \mathrm{Ti}+\mathrm{NiTi}$ ve $\mathrm{Ni}_{3} \mathrm{Ti}$ fazlarından oluştuğu belirlenmiştir. Katıhal difüzyonuna bağlı olarak $\mathrm{NiTi}_{2}$ faz miktarı azalırken $\mathrm{Ni}_{3} \mathrm{Ti}$ ve NiTi fazlarının oluşumu gerçekleşir. NiTi ve $\mathrm{Ni}_{3} \mathrm{Ti}$ fazlarının oluşmasında önemli rol oynayan katı hal düfizyon hızı 1sıtma hızı ve hammaddelerin yoğunluğuna bağlıdır [31-33].

Belirlenen fazlar Şekil 8'de yer verilmiş olan üçlü faz diyagramı ile tespit edilmeye çalış1lmıştır. EDX analizi sonucu ve üçlü faz diyagramı ile $\mathrm{NiTi}, \mathrm{NiTi}_{2}, \mathrm{Ti}_{3} \mathrm{Al}$ ve $\mathrm{Ni}_{3} \mathrm{Ti} \mathrm{Ni}_{3} \mathrm{Ti}$ fazlarıla birlikte artık fazların( $\left.\mathrm{NiTi}_{2}+\mathrm{NiTi}, \mathrm{Ni}_{3} \mathrm{Ti}+\mathrm{NiTi}, \mathrm{Ti}_{3} \mathrm{Al}+\mathrm{NiTi}_{2}\right)$ oluşabileceği tespit edilmiştir. Aşağıda yer verilmiş olan üçlü faz diyagramı ile tespit edilmiş olan $\mathrm{NiTi}, \mathrm{NiTi}_{2}$ ve $\mathrm{Ti}_{3} \mathrm{Al}$ ana fazlar XRD analiz sonuçlarıyla uyuşmaktadır. Çalışmamız sonucunda elde etmiş olduğumuz sonuçlar ile literatür sonuçlarının benzer olduğu tespit edilmiştir [9, 34-35].

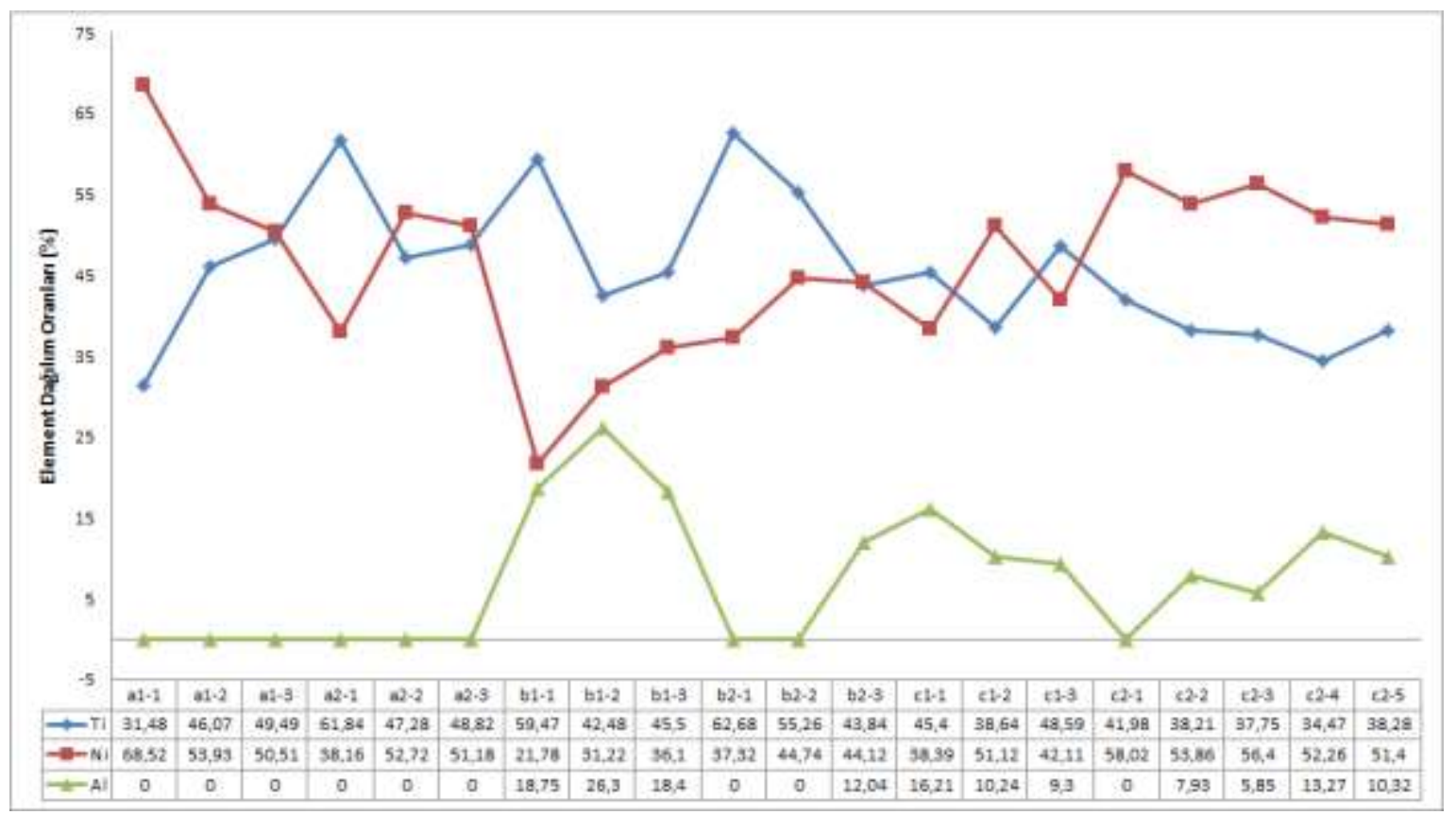

Şekil 7. NiTi, NiTi-ă̆\%2Alve NiTi-ăg\%4Al numunelerine ait EDX analizleri 


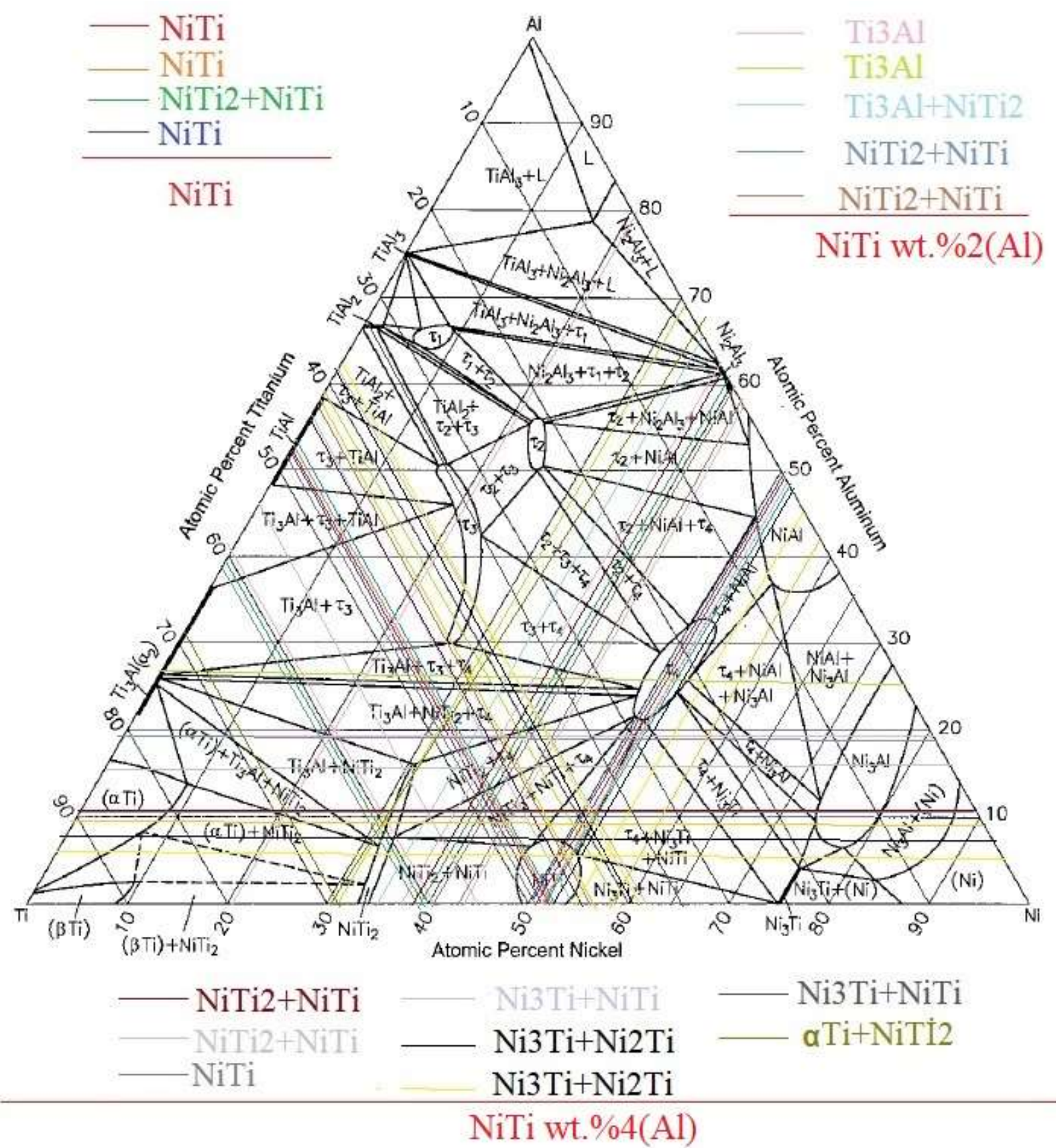

Şekil 8. Al-Ni-Ti diagramı [36]

SHS yöntemi ile üretilmiş numunelere ait XRD analiz sonuçlarına Şekil 9'da yer verilmiştir. Üretilen numunelerin XRD desenlerine incelendiğinde Al ilave edilmeden üretilen NiTi numunesi için ana fazın östenit NiTi fazı olduğu bunun yanında $\mathrm{NiTi}_{2}$ fazının da ikincil faz olarak varlığı görülmektedir. NiTi içerisine ilave edilen Al oranının artması ile ana faz olan östenit NiTi ve ikincil faz olan $\mathrm{NiTi}_{2}$ fazlarının yanında $\mathrm{Ti}_{3} \mathrm{Al}$ fazının oluştuğu görülmektedir. $\mathrm{Al}$ oranının artması ile $\mathrm{Ti}_{3} \mathrm{Al}$ fazının da arttığı anlaşılmaktadır. Ayrıca $700^{\circ} \mathrm{C}$ 'de titanyum partiküller çevresinde oluşan ince $\mathrm{Al}_{3} \mathrm{Ti}$ fazının ise $850{ }^{\circ} \mathrm{C}$ 'de $\mathrm{Ti}_{3} \mathrm{Al}$ ve AlTi fazına dönüştüğünü belirtilmiştir [29, 37].

Toz metalürjisi ile üretilen NiTi numunelerinin mikroyapılarında austenit NiTi, martensit NiTi ve $\mathrm{NiTi}_{2}$ fazlarının oluştuğu birçok araştırmacı tarafından belirtilmektedir [31, 38-40]. SHS yönteminde üretilen NiTi malzemede $\mathrm{NiTi}_{2}$ fazın varlığ $\breve{g}_{1}$ kaçınılmaz olmasının temel sebebi bu fazın tercihen oluşmasıyla ilgilidir [41]. Salvetr vd. [12] yapmış oldukları çalışmada $981^{\circ} \mathrm{C}$ sıcaklıkta oluşan ekzotermik reaksiyon etkisi ile $\mathrm{NiTi}, \mathrm{NiTi}_{2}, \mathrm{MgNi}$ ve $\mathrm{Ni}_{3} \mathrm{Ti}$ fazlarının oluştuğunu, sıcaklık $1097^{\circ} \mathrm{C}$ ulaştığında ötektik dönüşümün gerçekleştiğini, geri kalan ise $1147^{\circ} \mathrm{C}$ ise $\mathrm{MgNi}_{2}$ fazı içerdiğini belirtmişlerdir. 
Daha önce yapılan çalışmalarda $1050^{\circ} \mathrm{C}$ sıcaklıkta oluşan fazların $\mathrm{NiTi}_{2}$ ve NiTi fazlarına karş1ık geldiğini $1200^{\circ} \mathrm{C}$ ise $\mathrm{B}_{2} \mathrm{TiNi}\left(\mathrm{CsCl}\right.$ yapısı)varlığı doğrulanırken $\mathrm{NiTi}_{2}$ (Yüzey merkezli kübik yapı) ve $\mathrm{Ni}_{4} \mathrm{Ti}_{3}$ (Rhombohedral yapı) fazlarının ise zayıf piklere sahip olduğunu araştırmacılar tarafından belirtmişlerdir. Bu çalışmada numuneler SHS ile üretildikleri için mikroyapıda oluşan fazların oranları ilave edilen $\mathrm{Al}$ ile değişmektedir. $\mathrm{Ti}_{3} \mathrm{Al}$ fazı oluşurken diğer fazların azalması beklenirdi ancak XRD piklerinde bu durum belirgin şekilde görülmemektedir. Bunun sebebi numune yüzeyindeki kirliliklerden veya pürüzlülüklerden kaynaklanabilir.

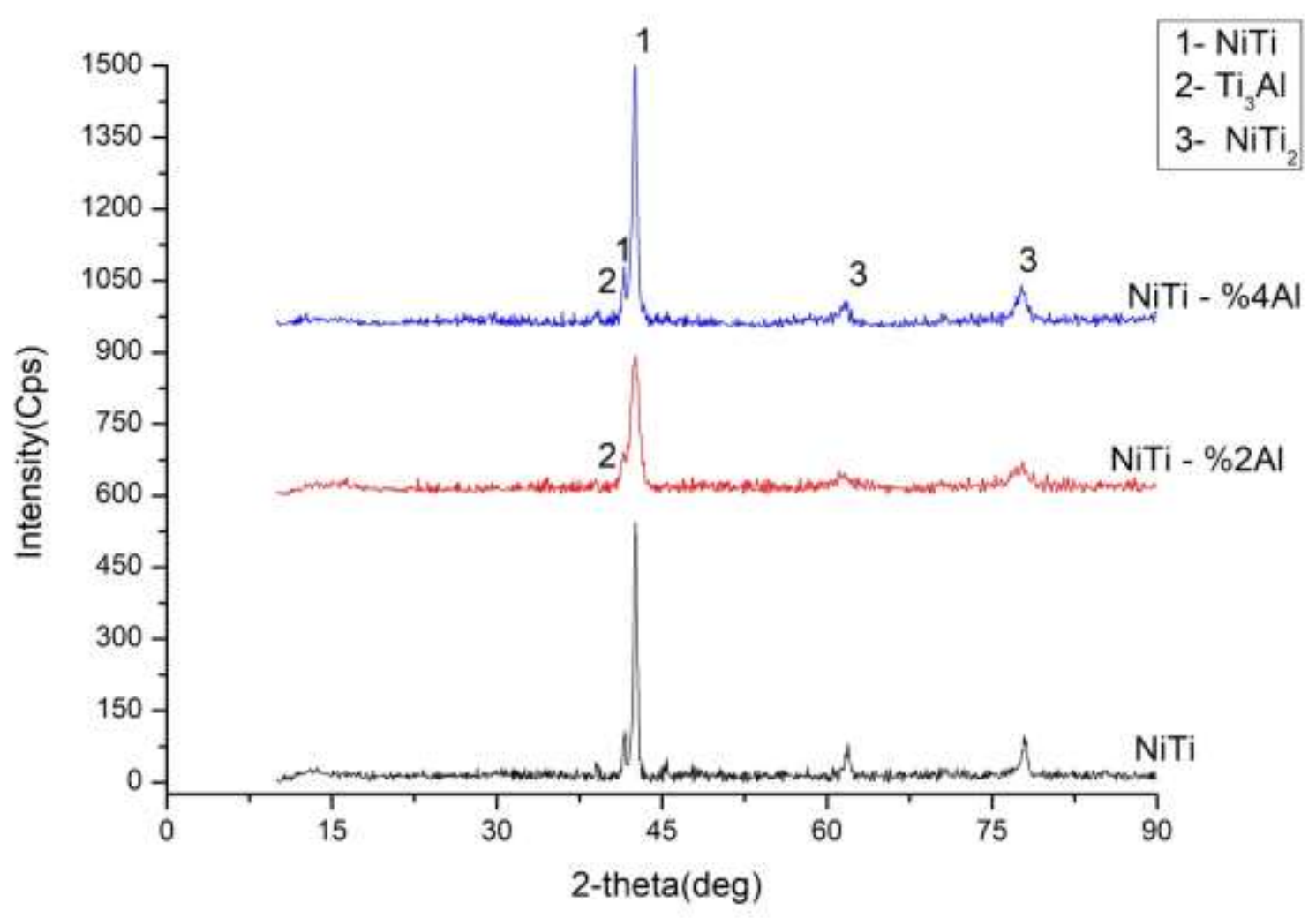

Şekil . NiTi, NiTi ağ. \%2Al ve NiTi ağ. \%4Al numunelerine ait XRD analiz sonuçları

Şekil 10'da mikrosertlik ölçüm sonuçlarına ait grafiğe yer verilmiştir. Mikrosertlik ölçümlerde elde edilen en yüksek değerin $301,2 \mathrm{HV}_{0.5}$ ile saf NiTi'de en düşük değer ise $176.8 \mathrm{HV}_{0.5}$ ile NiTiağ.\%4(Al) numunesinden ölçülmüştür. Yine aynı şekilde ortalama mikrosertlik değerlerinin ölçüm sonuçlardan görüldügü üzere en düşük ölçüm değeri 217,3 HV H..5 $\mathrm{NiTi-ağ. \% 4(Al)} \mathrm{numunesi} \mathrm{ait} \mathrm{olduğu}$ tespit edilmiştir (Şekil 10).

Gözenek oranı düşük Al ilavesiz NiTi alaşımında en yüksek mikrosertlik ölçüm değeri ile sonuçlanırken, NiTi-ăg.\%4(Al) numunesindeki gözenekliliği fazla olması nedeniyle daha düşük mikrosertlik değerleri ile sonuçlanmıştır. Baumann 2004 yllında yapmış olduğu bir çalışmada NiTi alaşımının mikrosertlik değerinin yaklaşık 300 ila $350 \mathrm{Hv}$ arasında olduğunu ifade etmiştir [42].

NiTi ve NiTiAl ile yapılan literatür incelemeleri sonucunda mikrosertlik ölçümlerde elde edilen en yüksek değer 362,4 Hv ile sonuçlanırken en düşük mikrosertlik değerinin ise $81,4 \mathrm{Hv}$ ile sonuçlandığ1 tespit edilmiştir [43-45]. Bizim elde etmiş olduğumuz mikrosertlik değerleriyle (Şekil 10) uyumlu olduğu görülmektedir. 


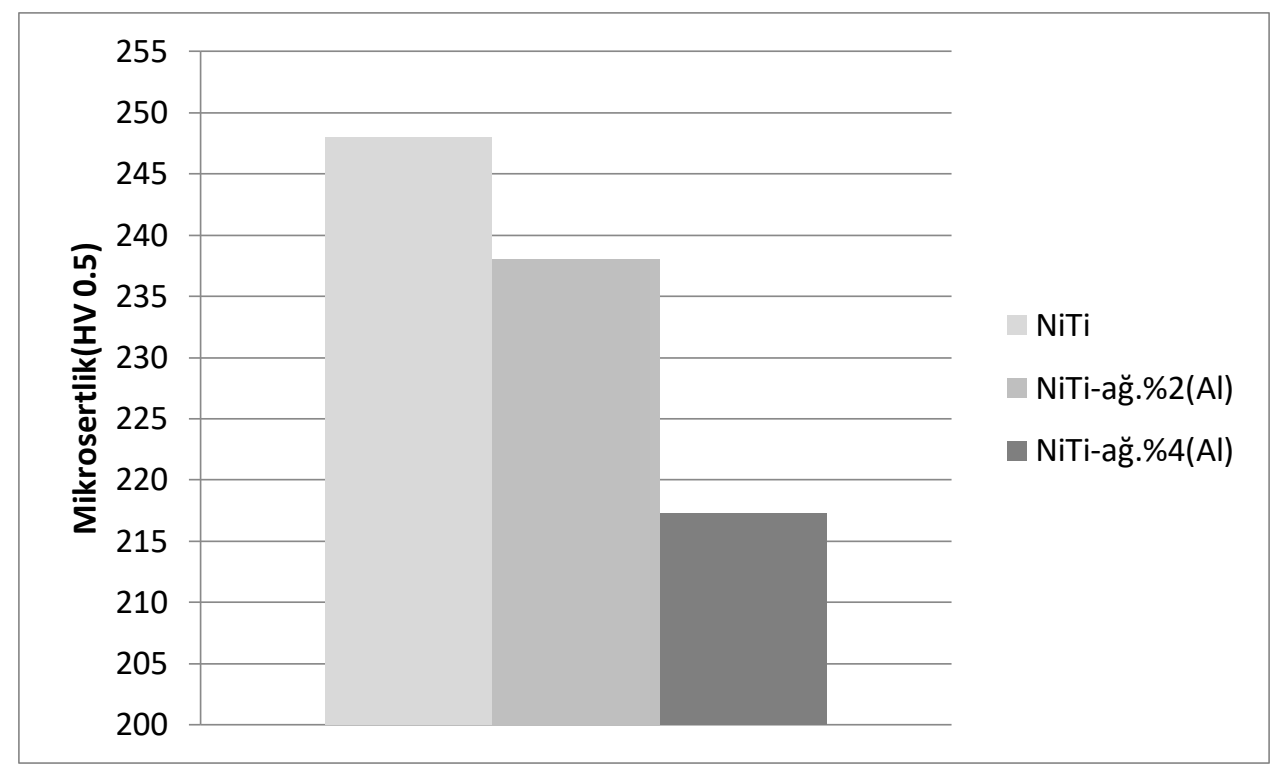

Şekil 10. Mikrosertlik ölçüm sonuçları $\left(\mathrm{HV}_{0.5}\right)$

\section{Sonuç ve Öneriler}

$\mathrm{Bu}$ çalışmada; eş atomlu NiTi toz karışımına ağ.\%2 Al, ağ.\%4 Al ilave edilerek SHS yöntemi ile NiTiAl numuneleri üretildi ve çalışma neticesinde aşağıdaki sonuçlar elde edildi:

a) Eş atomlu NiTi ve Al ilaveli NiTiAl alaşımları SHS yöntemi ile başarılı bir şekilde üretilmiştir.

b) $\mathrm{Al}$ içeriğine bağlı olarak gözeneklerin arttı̆̆ tespit edilmiştir.

c) Yanma kanalların Al içeriğine bağlı olarak azaldığı, kanalların daha çok numune orta kısımlarında oluştuğu makro resimlerden belirlenmiştir.

d) Yanma kanalları ateşleme yönüne dik veya paralel bir şekilde oluşmuştur.

e) $\mathrm{NiTi}, \mathrm{NiTi}_{2}$ ve $\mathrm{Ti}_{3} \mathrm{Al}$ fazlarının oluştuğu XRD analizi sonucunda tespit edilmiştir

f) Yapılan mikrosertlik test ölçüm sonuçlarına göre Al içeriğine bağlı olarak sertliğin düştüğü tespit edilmiştir. Buna göre en yüksek ölçüm değerinin $301,2 \mathrm{HV}_{0.5}$ ile saf NiTi numunesinde elde edilirken en düşük değer ise $176.8 \mathrm{HV}_{0.5}$ ile NiTi - ağ.\%4(Al) numunesinden ölçülmüsştür.

\section{Yazarların Katkısı}

Çalışmada tüm katkı yazara aittir.

\section{Çıkar Çatışması Beyanı}

Herhangi bir çıkar çatışması bulunmamaktadır.

\section{Araştırma ve Yayın Etiği Beyanı}

Yapılan çalışmada araştırma ve yayın etiğine uyulmuştur.

\section{Kaynaklar}

[1] Tosun G., Kilic M., Ozler L., Tosun N. 2018. Characterization of a Porous Nickel-Titanium Alloy Produced with Self-Propagating High-Temperature Synthesis. MTAEC9, 52 (4): 435.

[2] Shanmugavel R., Mokkandi P., Jayamani M., Rajini N., Uthayakumar M., Thirumalaikumaran S. 2017. Mechanical and Machinability characteristics of Al-NiTi composites reinforced with SiC particulates. J Aust Ceram Soc., 53: 177-185.

[3] Velmurugan C., Senthilkumar V., Dinesh S., Arulkirubakaran D. 2018. Review on phase transformation behavior of NiTi shape memory alloys. Mater Today Proc., 5: 14597-14606. 
[4] Yener T., Siddique S., Walther F., Zeytin S. 2015. Effect of Electric Current on the Production of NiTi Intermetallıcs Via Electric-Current-Activated Sintering. Materiali In Tehnologije, 49: 721.

[5] Farvizi M., Akbarpour R.M., Ahn H-D., Kim S.H. 2016. Compressive behavior of NiTi-based composites reinforced with alumina nanoparticles. J Alloys Compd., 688: 803-807.

[6] Zhao C., Liang H., Luo S., Yang J., Zemin Wang Z. 2020. The effect of energy input on reaction, phase transition and shape memory effect of NiTi alloy by selective laser melting. J Alloys Compd 817: 153288.

[7] Zeng Z., Cong B.Q., Oliveira J.P., Ke W.C., Schell N., Peng B., Qi Z.W., Ge F.G., Zhang W., Ao S.S. 2020. Wire and arc additive manufacturing of a Ni-rich NiTi shape memory alloy: microstructure and mechanical properties. Addit Manuf., doi: https://doi.org/10.1016/j.addma.2020.101051.

[8] Lou J., He H., Li Y., Zhu C., Chen Z., Liu C., 2016. Effects of high O contents on the microstructure, phase-transformation behaviour, and shape-recovery properties of porous NiTibased shape-memory alloys. Materials and Design, 106: 37-44.

[9] Xu J.L., Bao L.Z., Liu A.H., Jin X.F., Luo J.M., Zhong Z.C., Zheng Y.F. 2015. Effect of pore sizes on the microstructure and properties of the biomedical porous NiTi alloys prepared by microwave sintering. J Alloys Compd., 645: 137-142.

[10] Kurt B., I. Somunkiran İ. 2008. Interface microstructure of porous $\mathrm{Ni}-\mathrm{Ti}$ and $\mathrm{Co}-\mathrm{Cr}-\mathrm{Mo}$ powder alloy couple fabricated by SHS process. Powder Metallurgy, 51 (3): 254-256.

[11] Gunter V., Yasenchuk Y., Gunther S., Marchenko E., Yuzhakov M. 2019. Biocompatibility of Porous SHS-TiNi. Materials Science Forum, 970: 320-327.

[12] Salvetr P., Školáková A., Novák P. 2017. Effect of magnesium addition on the structural homogeneity of NiTi alloy produced by self-propagating high-temperature synthesis. Kovove Mater., 55: 379-383.

[13] Dagdelen F., Balci E., Qader N.I, Ozen E., Kok M., Kanca S.M., Abdullah S.S., Mohammed S.S. 2020. Influence of the $\mathrm{Nb}$ Content on the Microstructure and Phase Transformation Properties of NiTiNb Shape Memory Alloys. JOM, 72: 4.

[14] Duan S., Shi X., Zhang M., Li B., Dou G., Guo H., Guo J. 2019. Determination of the thermodynamic properties of $\mathrm{Ni}-\mathrm{Ti}, \mathrm{Ni}-\mathrm{Al}$, and $\mathrm{Ti}-\mathrm{Al}$, and nickel-rich Ni-Al-Ti melts based on the atom and molecule coexistence theory. J Mol Liq., 294: 111462.

[15] Shia J., Zheng A., Lin Z., Chen R., Zheng J., Cao Z. 2019. Effect of process control agent on alloying and mechanical behavior of L21 phase Ni-Ti-Al alloys. J Mater Sci Eng A, 740-741: 130-136.

[16] Chen H., Zheng J.L., Zhang X.F., Zhang H. 2017. Thermal stability and hardening behavior in superelastic Ni-rich Nitinol alloys with Al addition. J Mater Sci Eng A, 708: 514-522.

[17] Zhao Y., Wang L., Sun Y., Liu H., Jiang C., Ji V., Li W. 2019. Influences of Al and Ti particles on microstructure, internal stress and property of Ni composite coatings. J Alloys Compd., 793: 314-325.

[18] Kim D.H., Kim W.T., Kim D.H. 2004. Formation and crystallization of Al-Ni-Ti amorphous alloys. J Mater Sci Eng A, 385: 44-53.

[19] Hsiung L-C., Sheu H-H. 2009. A comparison of the phase evolution in Ni, Al, and Ti powder mixtures synthesized by SHS and MA processes. J Alloys Compd., 479: 314-325.

[20] Sichani R.H., Salehi M., Edris H., Farani T.M. 2017. The effect of APS parameter on the microstructural, mechanical and corrosion properties of plasma sprayed $\mathrm{Ni}-\mathrm{Ti}-\mathrm{Al}$ intermetallic coatings. Surf Coat Technol., 309: 959-968.

[21] Hu R., Nash P., Chen Q., Zhang L., Du Y. 2009. Heat capacities of several Al-Ni-Ti compounds. Thermochimica Acta, 486: 57-65.

[22] Kılıç M., Beken M., Özdemir N. 2019. Investigation of the Effect of Sintering Process After Shs Processing on Intermetallic Coating. Firat Üniversitesi Müh. Bil. Dergisi, 31 (1): 167-176.

[23] Monogenov A.A., Gunther V.E., Ivchenko O.A., Stebluk A.N., Radkewich A.A., Ariamkin A.A., Shtofin S.S. 2017. Structure and Properties of Porous Alloys Based on NiTi Doped by Al, Fabricated by SHS-method, in Shape Memory Biomaterials and Implants in Medicine. KnE Materials Science, 62-71.

[24] Morsi K. 2001. Review: reaction synthesis processing of Ni-Al intermetallic materials. J Mater Sci Eng A, 299: 1-15. 
[25] Sina H., Surreddi B.K., Iyengar S. 2016. Phase evolution during the reactive sintering of ternary Al-Ni-Ti powder compacts. J Alloys Compd., 661: 294-305.

[26] Kaya M., Orhan N., Kurt B. 2009. Effect of solution treatment under load on microstructure and fabrication of porous NiTi shape memory alloy by self-propagating high temperature synthesis. Powder Metallurgy, 52 (1): 36-41.

[27] Kaya M., Orhan N., Tosun G. 2010. The effect of the combustion channels on the compressive strength of porous NiTi shape memory alloy fabricated by SHS as implant material. Curr Opin Solid State Mater Sci., 14: 21-25.

[28] Dong H.X., Jiang Y., He Y.H., Song M., Zou J., Xu N.P., Huang B.Y., Liu C.T., Liaw P.K. 2009. Formation of porous $\mathrm{Ni}-\mathrm{Al}$ intermetallics through pressureless reaction synthesis. J Alloys Compd., 484: 907-913.

[29] Novák P., Mejzlíková L, Michalcová A., Čapek J., Beran P., Vojtěch D. 2013. Effect of SHS conditions on microstructure of NiTi shape memory alloy. Intermetallics, 42: 85-91.

[30] Liu B., Liu Z., Liu X., Wang W., Wang L. 2013. Effect of sintering temperature on the microstructure and mechanical properties of Ti50Ni50 and Ti47Ni47Al6 intermetallic alloys. J Alloys Compd., 578: 373-379.

[31] Tosun G., Ozler L., Kaya M., Orhan N. 2009. A study on microstructure and porosity of NiTi alloy implants produced by SHS. J Alloys Compd., 487: 605-611.

[32] Khanlari K., Ramezani M., Kelly P., Cao P., Neitzert T. 2018.Synthesis of As-sintered 60NiTi Parts with a High Open Porosity Level. Materials Research, 21 (5): e20180088.

[33] Salvetr P., Školáková A., Hudrisier C., Novák P., Vojtěch D. 2018. Reactive Sintering Mechanism and Phase Formation in Ni-Ti-Al Powder Mixture During Heating. Materials, 11: 689.

[34] Xu J.L., Bao L.Z., Liu A.H., Jin X.J., Tong Y.X., Luo J.M., Zhong Z.C., Zheng Y.F. 2015. Microstructure, mechanical properties and superelasticity of biomedical porous NiTi alloy prepared by microwave sintering. Mater Sci Eng C, 46: 387-393.

[35] Mousavi T., Karimzadeh F., Abbasi H.M. 2009. Mechanochemical assisted synthesis of NiTi intermetallic based nanocomposite reinforced by Al2O3. J Alloys Compd., 467: 173-178.

[36] Raghavan V. 2005. Al-Ni-Ti (Aluminum-Nickel-Titanium). J Phs Eqil and Diff, 26: 268-272.

[37] Gashti O.S., Shokuhfar A., Ebrahimi-Kahrizsangi R., Nasiri-Tabrizi B. 2010. Synthesis of nanocrystalline intermetallic compounds in $\mathrm{Ni}-\mathrm{Ti}-\mathrm{Al}$ system by mechanothermal method. $\mathrm{J}$ Alloys Compd., 491: 344-348.

[38] Li P., Wang Y., Meng F., Cao L., He Z. 2019. Effect of Heat Treatment Temperature on Martensitic Transformation and Superelasticity of the Ti49Ni51 Shape Memory Alloy. Materials, 12: 2539 .

[39] Kilic M., Yenigun B., Bati B., Balalan Z., Kirik İ. 2019. Effect of $\mathrm{Cu}$ addition on porous NiTi SMAs produced by self propagating high-temperature Synthesis. Materials Testing, 61 (12): 1140-1144.

[40] Aksöz S. 2017. Microstructural and Mechanical Investigation of NiTi Intermetallics Produced by Hot Deformation Technique. Arab J Sci Eng., 42: 2573-2581.

[41] Novák P., Skoláková A., Pignol D., Průš F., Salvetr P., Kubatík F.T., Perriere L., Karlík M. 2016. Finding the energy source for self-propagating high-temperature synthesis production of NiTi shape memory alloy. Mater Chem Phys., 181: 295-300.

[42] Baumann A.M. 2004. Nickel-titanium: options and challenges. Dent Clin N Am, 48: 55-67.

[43] Ye N., Ren X., Liang J. 2020. Microstructure and mechanical properties of Ni/Ti/Al/Cu composite produced by accumulativeroll bonding (ARB) at room temperature. J. Mater. Res. Technol., 9 (3): 5524-5532.

[44] Sang C., Cai X., Zhu L., Ren X., Niu G., Wang X., Feng P. 2020. Interfacial microstructure of $\mathrm{Ti} / \mathrm{Ni}$ joints with $\mathrm{Ti}-\mathrm{Al}$ interlayer by rapid thermal explosion bonding in vacuum. Vacuum, 171: 109028.

[45] Čapek J., Kučera V., Fousovà M., Vojtěch D. 2013. Preparation of The NiTi Shape Memory Alloy By The Te-Shs Method - Influence of the Sintering Time. METAL 2013-22nd International Conference on Metallurgy and Materials, Conference Proceedings, 15-17 May, Brno, Czech Republic, E. 